\title{
Evaluation of Biomechanical Traction of Incisional Gastropexy and Scarification Gastropexy Techniques in Dogs
}

\author{
Stefanes Antunes de Ornellas', Ana Claudia Bireahls², Natalia Helena Meneguin ${ }^{3}$, \\ Tais Harumi de Castro Sasahara ${ }^{4}$, Paola Castro Moraes ${ }^{3}$, Maria Luiza Rodrigues de Souza ${ }^{5}$ \& Leonardo Martins Leal'
}

\begin{abstract}
Background: Gastropexy is used to correct gastric dilatation volvulus, a disease that usually affects large and giant dogs and leads to death in 23.4 - $43 \%$ of patients. This study aimed to evaluate the biomechanical traction of 2 gastropexy techniques, incisional gastropexy and scarified gastropexy, in $10 \mathrm{dog}$ cadavers. Incisional gastropexy comprises a single incision in the abdominal wall and another incision in the stomach wall in the pyloric region followed by simple continuous sutures. The scarification technique creates scarification along the stomach borders of the pexy. Thereby, knowing that both techniques are successful, the biomechanical traction of each technique was compared.

Materials, Methods \& Results: A total of 10 animals without defined breed weighing from 6.4 - $43.0 \mathrm{~kg}$ were allocated into 2 equal groups (GE [scarified gastropexy] and GI [incisional gastropexy]). Incisional gastropexy was performed with a simple continuous suture pattern in the GI group and scarified gastropexy with an interrupted simple suture pattern was performed in the GE group. Absorbable 2-0 monofilament yarn (polygllecaprone 25) was used for sutures in both groups. Rectangular segments of the gastric antrum were collected from the right abdominal wall and from the bottom of the stomach at the left abdominal wall, which were subjected to a traction test. The scarification technique was easier, faster, and used less surgical sutures than the incisional technique. Both techniques were effective regardless of the site applied, with no significant differences. There was a difference in stretching depending on location.

Discussion: The pathogenesis of gastric dilatation volvulus (GDV) is unknown. However, gas accumulation inside the gastric chamber may lead to organ dilation and consequently cause torsion of the cardia region and pyloric antrum, resulting in strangulation of blood vessels and nerves. This torsion could cause stomach ischemia followed by organ necrosis if early emergency care is not provided. In addition, vessel strangulation my lead to a systemic syndrome resulting in shock. The disease presents acute and non-specific clinical signs such as weight loss, vomiting, and abdominal intumescence. Patients with risk factors such as reduced gastric motility, delayed stomach replenishment, lower weight, advanced age, or presence of a foreign body may present with poor prognosis. Once GDV becomes an emergency, surgical correction with the most efficient surgical techniques and procedures is necessary to guarantee patient survival. Based on the results obtained, both the scarified and incisional gastropexy techniques are more efficient than other techniques. In addition, the scarified technique with interrupted simple stitches stood out when compared to the incisional technique with a continuous simple suture pattern as it was faster and used less suture thread. The incisional technique, on the other hand, provides good juxtaposition of the edges of the wounds, avoiding the exposure of muscle tissue, as well as adhesions from other organs. The knowledge of those factors promotes positive effects on the effectiveness of an emergency surgical approach for patients with GDV, since it allows less surgical time, as well as less anesthetic time. Based on the results obtained during the biomechanical traction tests of the study, it was concluded that both scarified gastropexy with interrupted single stitches and incisional gastropexy with a continuous single stitch may be efficient. The scarified technique stood out when compared to the incisional technique as it required less time and used less sutures.
\end{abstract}

Keywords: biomechanical assay, surgery, digestive, gastric volvulus dilatation, syndrome, small animal. 


\section{INTRODUCTION}

Gastric dilatation volvulus (GDV) is a severe syndrome that is commonly seen in small animal clinics $[10,11]$. It affects large and giant dogs with deep thoraxes and is rarely observed in small dogs or cats [5]. Although its etiopathogenesis is poorly understood, gastropexy is a treatment to prevent the recurrence of torsion $[7,16]$.

Gastropexy for GDV consists of replacement and fixation of the stomach in a location anatomically compatible with its original position through permanent adhesion of the pyloric antrum to the right abdominal wall to prevent recurrence of GDV [9].

Gastropexy is also performed in cases of gastroesophageal intussusception, which is often confused with esophageal hiatus hernia [16]. The cause is generally unknown but is associated with irritability and hypermotility of the digestive tract and the concomitant presence of hiatus herniation [15]. Various gastropexy techniques, such as incisional, tube, circumcostal, muscle fold, belt loop, gastrocolopexy, and laparoscopic, have been reported in the literature $[15,16]$.

Although the scarification gastropexy technique is not common in the literature, it is used by many veterinary surgeons. Furthermore, no reports of traction tests for any gastropexy technique, including the classic incisional technique of gastropexy, were found in the literature.

The aim of this study was to evaluate traction resistance with the incisional and scarification gastropexy techniques in 10 dog cadavers to provide more information on surgical techniques for GDV correction.

\section{MATERIALS AND METHODS}

\section{Animals}

A total of 10 dog cadavers without defined breed weighing from $6.4-43.0 \mathrm{~kg}$, between 5 - 10 years of age, were allocated into 2 groups (GI and GE). In the GI group, incisional gastropexy with a simple continuous suture pattern was performed, and in the GE group, scarified gastropexy with an interrupted simple suture pattern was performed. The two techniques were performed in the pylorus antrum region (fixed to the right abdominal wall) and in the fundic region (fixed to the left abdominal wall) in all animals. At the end of the experiment, there was an equal distribution between the techniques and the position of the gastropexy.

All dogs were obtained from veterinary clinics in Maringá, and their former guardians had previously authorized their use by the University Center - Unguay. The incisional gastropexy technique was performed with a standardized incision of $3 \mathrm{~cm}$ in the seromuscular layer of the stomach and another in the lateral abdominal wall, thus exposing the peritoneum and the internal fascia of the abdominal transverse muscles [9]. It is noteworthy that the size of the incision made in the abdominal wall was equivalent to that made in the antrum or gastric fundus. The edges of the incisions were sutured with absorbable 2-0 monofilament yarn (polyglecaprone 25) ${ }^{1}$ in a single continuous double pattern (Figure 1).

\section{Incisional and scarification techniques}

In the GE group, scarification was performed in the pyloric antrum or gastric fundus ( $3 \mathrm{~cm}$ in diameter) and in the abdominal wall (3 $\mathrm{cm}$ in diameter) [Figure 2]. For coaptation of these two structures, three simple interrupted stitches were made with absorbable 2-0 monofilament yarn (poliglecaprone 25) ${ }^{1}$.

After performing the surgical techniques, rectangular segments $(10 \mathrm{~cm} \times 5 \mathrm{~cm})$ of the gastric antrum were collected from both groups from the right abdominal wall and the bottom of the stomach at the left abdominal wall. Samples were frozen for storage until all techniques were done.

Samples were thawed at room temperature, their thicknesses were measured using a caliper, and they were subjected to a traction test using a tensiometer (EMIC 23-5D) ${ }^{2}$. Data was recorded using Tesc ${ }^{2}$ software regarding the force required to tear each sample (Figure 3).

Tests were performed at the Iguatemi Experimental Farm (FEI) located on the campus of the State University of Maringá. All samples were evaluated on the same day in the traction machine to avoid possible variations in the calibration of the apparatus.

The experiment was designed to be entirely randomized in a $2 \times 2$ factorial scheme, where the two techniques of gastropexy were performed. The data were normally distributed (Shapiro-Wilk test; $P \leq 0.05$ ) and homoscedasticity of variances was confirmed (Levene's test; $P \leq 0.05$ ) before analysis of variance (ANOVA).

\section{Statistical analysis}

The data were compared by ANOVA at the 5\% significance level by the F test. Comparison of means was performed by $t$-test for variables with significant $\mathrm{F}$ values at a 5\% significance level. These analysis were performed using Sisvar [4] software version 5.3. 


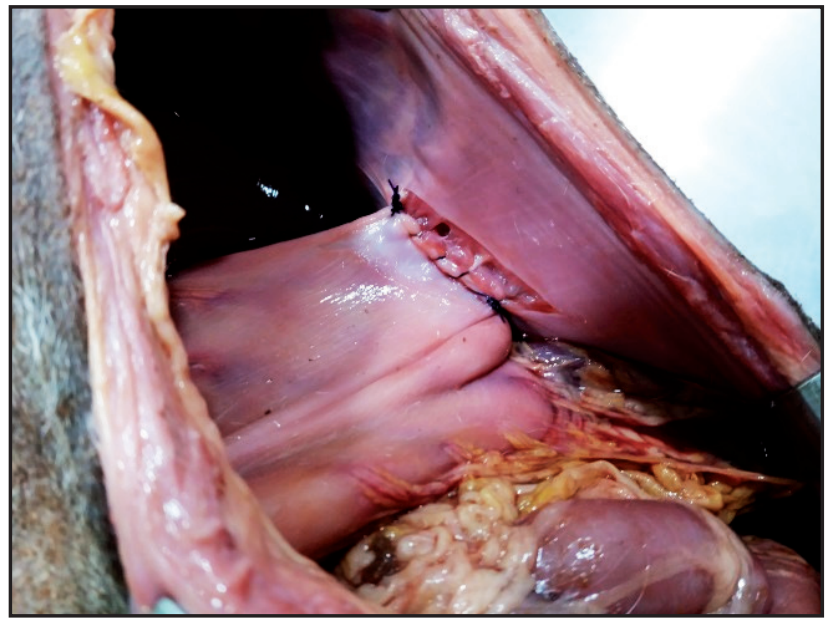

Figure 1. Incisional gastropexy technique with continuous simple suture pattern. Note that the first line of the continuous suture has already been performed.

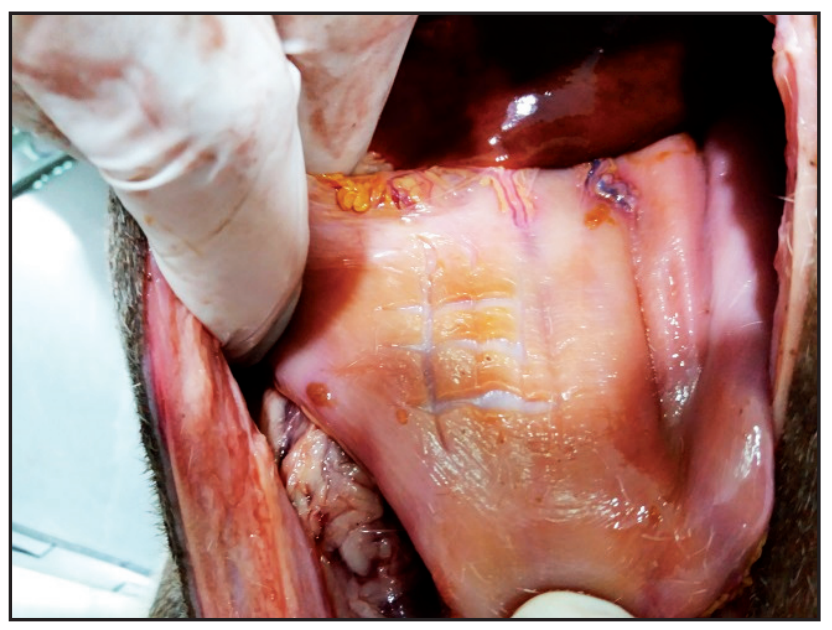

Figure 2. Scarified gastropexy technique with interrupted simple suture pattern. Note the presence of the scarified technique in the pyloric region.

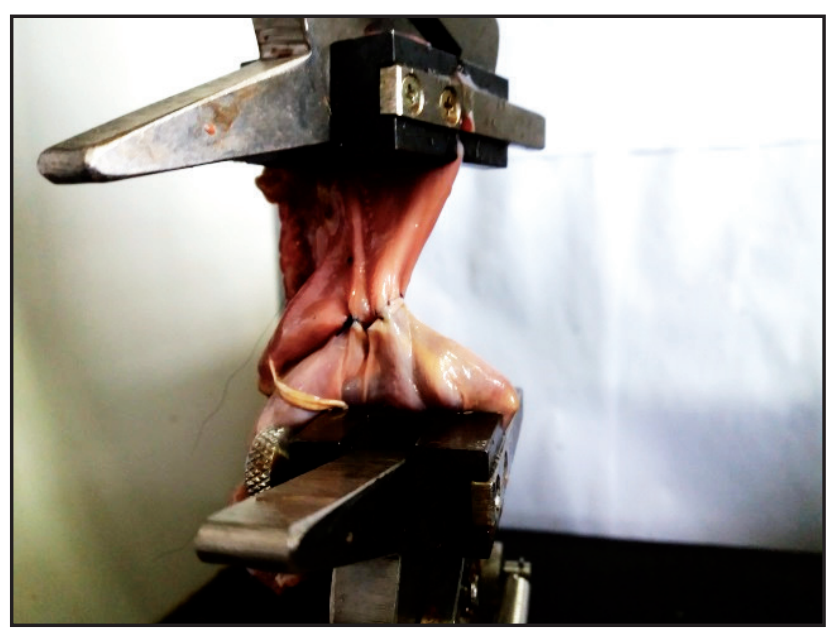

Figure 3. Tensile test on the EMIC 23-5D tensiometer.

\section{RESULTS}

Greater ease of surgery, faster execution, and less surgical sutures were associated with the scarification technique. In the incisional technique, the greatest advantage was the good coaptation of the wound edges, avoiding the exposure of muscle tissue of both the stomach and the abdominal wall to the abdominal cavity. The traction test values for each sample are described in Table 1.

There was no interaction $(P>0.05)$ between the gastropexy technique (scarified or incisional) and application site (background or pylorus) for variables related to traction biomechanics evaluated in this study.

Traction was not influenced $(P>0.05)$ by the technique used or by the application site (Table 2 ), presenting an overall mean (mean \pm standard deviation [SD]) of $2.3 \pm 1.17 \mathrm{~N} / \mathrm{mm}^{2}$. Similarly, the maximum force was not influenced $(P>0.05)$ by the gastropexy technique or by the application site, presenting an overall mean (mean \pm SD) of $31.4 \pm$ $11.19 \mathrm{~N}$.

The gastropexy technique did not influence $(P$ $>0.05)$ stretching (expressed as a percentage). However, a difference $(P<0.05)$ in stretching was observed depending on the application site. When the techniques were applied to the background, the elongation was greater $(P<0.05)$ than when applied to the pylorus.

Deformation was not influenced $(P>0.05)$ by the technique used or by the application site (Table 2 ), presenting an overall mean (mean \pm SD) of 44.3 $\pm 14.02 \mathrm{~mm}$.

Table 1. Absolute values of the points of rupture of each sample.

\begin{tabular}{|c|c|c|c|c|c|c|c|}
\hline \multicolumn{4}{|c|}{ Background } & \multicolumn{4}{|c|}{ Pylorus } \\
\hline \multicolumn{2}{|c|}{ Scarified } & \multicolumn{2}{|c|}{ Incisional } & \multicolumn{2}{|c|}{ Incisional } & \multicolumn{2}{|c|}{ Scarified } \\
\hline Sample & $\mathrm{N} / \mathrm{mm}^{2}$ & Sample & $\mathrm{N} / \mathrm{mm}^{2}$ & Sample & $\mathrm{N} / \mathrm{mm}^{2}$ & Sample & $\mathrm{N} / \mathrm{mm}^{2}$ \\
\hline 01 & 1.73 & 02 & 1.21 & 01 & 2.22 & 02 & 3.80 \\
\hline 03 & 1.76 & 04 & 2.96 & 03 & 1.81 & 04 & 1.90 \\
\hline 05 & 1.60 & 06 & 3.07 & 05 & 2.06 & 06 & 3.50 \\
\hline 07 & 2.50 & 08 & 5.00 & 07 & 3.63 & 08 & 0.50 \\
\hline 09 & 2.66 & 10 & 1.71 & 09 & 1.50 & 10 & 0.48 \\
\hline
\end{tabular}


Table 2. Averages with standard deviations for all variables evaluated in the comparison between gastropexy techniques and its place of application.

\begin{tabular}{|c|c|c|c|c|}
\hline \multirow{2}{*}{ Technique } & \multicolumn{2}{|c|}{ Place } & \multirow{2}{*}{ Average } & \multirow{2}{*}{$\begin{array}{c}\text { Coefficient of } \\
\text { variation }\end{array}$} \\
\hline & Background & Pylorus & & \\
\hline \multicolumn{5}{|c|}{ Traction $\left(\mathrm{N} / \mathrm{mm}^{2}\right)$} \\
\hline Scarified & $2.1 \pm 0.49$ & $1.9 \pm 1.48$ & $2.0 \pm 1.04$ & \\
\hline Incisional & $2.8 \pm 1.47$ & $2.2 \pm 0.82$ & $2.5 \pm 1.15$ & 50.93 \\
\hline Average & $2.4 \pm 1.10$ & $2.1 \pm 1.14$ & $2.3 \pm 1.17$ & \\
\hline \multicolumn{5}{|c|}{ Maximum force (Newton) } \\
\hline Scarified & $27.6 \pm 9.81$ & $26.0 \pm 12.80$ & $26.8 \pm 10.79$ & \\
\hline Incisional & $40.0 \pm 15.06$ & $31.8 \pm 3.56$ & $35.9 \pm 11.18$ & 35.66 \\
\hline Average & $33.8 \pm 13.65$ & $28.9 \pm 9.37$ & $31.4 \pm 11.19$ & \\
\hline \multicolumn{5}{|c|}{ Elongation (\%) } \\
\hline Scarified & $67.2 \pm 25.96$ & $49.6 \pm 20.42$ & $58.4 \pm 23.90$ & \\
\hline Incisional & $98.2 \pm 15.12$ & $60.4 \pm 28.15$ & $79.3 \pm 29.17$ & 33.38 \\
\hline Average & $82.7 \pm 25.85^{*}$ & $55.0 \pm 23.87 *$ & $68.9 \pm 23.00$ & \\
\hline \multicolumn{5}{|c|}{ Deformation (mm) } \\
\hline Scarified & $40.0 \pm 15.79$ & $41.4 \pm 20.30$ & $40.7 \pm 17.17$ & \\
\hline Incisional & $58.6 \pm 8.96$ & $45.6 \pm 10.99$ & $52.1 \pm 11.67$ & 31.65 \\
\hline Average & $40.7 \pm 17.17$ & $43.5 \pm 15.55$ & $44.3 \pm 14.02$ & \\
\hline
\end{tabular}

Significant differences by $t$ test are highlighted with asterisks $(P<0.05)$.

\section{DISCUSSION}

There are four phases of wound repair: hemostasis, acute inflammation, proliferation, and remodeling. Hemostasis occurs immediately after the injury, unless there is any coagulation disorder or extra factors [14]. Thus, even in a study in cadavers, the evaluation of traction can be useful to evaluate the best technique for sustaining the stomach in initial periods, in which there is still no wound healing.

In the present study, the incisional and scarified techniques were applied simultaneously in the same animal in an alternate and random manner. This was done to attenuate possible influences on the experiment, since the thicknesses of each sample may present considerable differences. This was determined to be the case as the force required for the rupture of each sample was significant (Table 1). In addition, it promoted greater standardization of samples.

Post mortem bacterial metabolism and the dissolution of animal tissue results in the production of alterations in color and texture, besides exerting direct or indirect influence on the process of establishment and resolution of rigor mortis [3].
Post mortem microbiome succession is a foreseeable and time-dependent process resulting in predictable changes in internal organ microbiomes.

In addition, low environmental temperatures or refrigeration inhibit autolysis and freezing induces the formation of intracellular and extracellular ice crystals, promoting the disruption of tissues and cells [6]. However, because this was a comparative study of two techniques in the same animals and under the same conditions, freezing does not reduce the credibility of the presented results.

Scarified gastropexy enabled greater speed during the procedure when compared to incisional gastropexy. This is due to the fact that only three single interrupted stitches were used during the execution of the scarified technique when compared to the doublelayer suture made in a continuous single pattern in the incisional gastropexy technique. In addition, during the execution of the scarified technique, less suture thread was used compared to the incisional technique. These factors (speed of execution and lower consumption of sutures) would certainly have positive effects in the surgical routines of clinics and veterinary hospitals, as surgery would become less expensive due to decreases 
in use of materials, including anesthesia. In addition, it may be favorable to maintain less foreign material in the surgical wound [9].

Different sutures for laparoscopic incisional colopexy in dogs (3-0 polyglactin thread and polypropylene) do not show significant differences in total surgical time [1,2]. However, the scarification technique was easier to perform and took less time and surgical sutures compared to the incisional technique.

In the incisional technique, the greatest advantage was the good coaptation of the wound edges, avoiding the exposure of muscle tissue from both the stomach and abdominal wall to the abdominal cavity. The best juxtaposition observed in the incisional technique certainly avoids the occurrence of unwanted adhesions of adjacent organs in the exposed muscle tissue. Visceral-parietal adhesions are common in the reconstruction of iatrogenic defects of the abdominal wall of rats [8].

In the present study, it was observed that in the traction area, both the scarified technique and the incisional technique seem effective, regardless of application to the pylorus or fundus, as there were no significant differences. However, no studies have described the minimum strength necessary for a gastropexy to be effective.

Considering the results in the present study, it is necessary to emphasize that patient survival depends not only on the surgical technique, but also on admission time and when surgery is performed [13].

When comparing two tendon-suturing techniques [12], it was found that the stitch in the "Loop" presented a significantly greater mean maximum rupture force than the stitch in " $X$ ". On the other hand, the results obtained in this study show that the maximum force not influenced by the gastropexy technique or by the region to which it was applied.

Elongation also had no influence, since the technique itself does not have the capacity to promote physical and chemical changes in the tissues to which they were applied. On the other hand, in the statistical analysis, it became evident that elongation was influenced depending on where the technique was applied: the elongation was greater when the techniques were applied in the background than when applied in the pylorus. It is very likely that the difference found in elongation is related to the characteristics of the gastric regions. This should not directly affect the choice of technique, since the position of the stomach that will undergo gastropexy correlates with the initial condition and not with the choice of the surgeon [9].

In this research, neither the technique used (scarified or incisional) nor the place of application promoted significant differences in deformation.

\section{CONCLUSIONS}

Based on the results obtained during the biomechanical traction tests of the study, it was concluded that both scarified gastropexy with interrupted single stitches and incisional gastropexy with a continuous single stitch may be efficacious. The scarified technique stood out when compared to the incisional technique as it required less time and used less sutures.

\section{MANUFACTURERS}

${ }^{1}$ Instron®. Norwood, MA, USA.

${ }^{2}$ Atramat ${ }^{\circledR}$. Internacional Farmacéutica S.A. Ciudad de México, D.F., México.

Acknowledgements. We thank the National Council for Scientific and Technological Development (CNPq), the University Center Ingá, and the State University of Maringá (UEM) for financial and technical collaboration for the development of this work. Also, we thank São Paulo State University "Júlio de Mesquita Filho" (UNESP) - Faculty of Agricultural and Veterinary Sciences (FCAV) for cooperation.

Ethical approval. This research was approved by the Ethical Committee for Animal Use (CEUA) of the Centro Universitário Ingá, PM36/2017, and was conducted under the ethical principles of the Sociedade Brasileira de Ciência em Animais de Laboratório. All applicable international, national, and/or institutional guidelines for the care of animals were followed.

Declaration of interest. The authors report no conflicts of interest. The authors alone are responsible for the content and writing of the paper.

\section{REFERENCES}

1 Brun M.V., Pippi N.L., Beck C.A.D.C., Contesini E.A., Chaves E., Pereira R.A., Stedile R., Gomes K., Schettini B.R., Rocha F., Bonfada A.T., Columé L.M. \& Vieira Jr. A.R.P. 2004. Resistência à tração de colopexias incisionais realizadas por cirurgia laparoscópica ou celiotomia em cães. Ciência Rural. 34(3): 839-845. DOI: 10.1590/S010384782004000300028 
2 Brun M.V., Pippi N.L., Beck C.A.D.C., Contesini E.A., Pereira R.A., Stedile R., Bonfada A.T., Bordin Â.I., Silva T.F., Columé L.M., Gomes K. \& Vieira Jr. A.R.P. 2004. Avaliação de dois diferentes fios de sutura para colopexia incisional laparoscopia em cães: estudo experimental. Brazilian Journal of Veterinary Research and Animal Science. 41(3): 154-161. DOI: 10.1590/S1413-95962004000300002

3 Erlandsson M. \& Munro R. 2007. Estimation of the post-mortem interval in beagle dogs. Science \& Justice. 47(4): 150-154. DOI: 10.1016/j.scijus.2007.09.005

4 Ferreira D.F. 2011. Sisvar: a computer statistical analysis system. Ciência e Agrotecnologia. 35(6): 1039-1042. DOI: 10.1590/S1413-70542011000600001

5 Grassato L., Spinella G., Musella V., Giunti M., Vilar J.M. \& Valentini S. 2020. Pre-and post-surgical evaluation of plasma lactate concentration in 45 dogs with gastric dilatation volvulus: A preliminary study. Heliyon. 6(1): e03307. DOI: 10.1016/j.heliyon.2020.e03307

6 Miller M.A. \& Zachary J.F. 2013. Mecanismos e morfologia de lesão, adaptação e morte celular. In: Zachary J. \& McGavin M.D. (Eds). Bases da Patologia em Veterinária. 6.ed. Rio de Janeiro: Elsevier, pp.2-43.

7 Paris J.K., Yool D.A., Reed N., Ridyard A.E., Chandler M.L. \& Simpson J.W. 2011. Chronic gastric instability and presumed incomplete volvulus in dogs. Journal of Small Animal Practice. 52(12): 651-655. DOI: 10.1111/j.17485827.2011.01137.x

8 Paulo N.M., Lima F.G., Siqueira Júnior J.T., Fleury F.F., Sant'ana F.J.F., Borges A.C. \& Telles T.C. 2005. Membrana de látex da seringueira (Hevea brasiliensis), com e sem polilisina a 0,1\% e tela de marlex na reconstrução de defeitos iatrogênicos da parede abdominal de ratos. Acta Cirúrgica Brasileira. 20(4): 305-310. DOI: 10.1590/S010286502005000400008

9 Radlinsky M.G. 2015. Cirurgia do Sistema Digestório. In: Fossum T.W. (Ed). Cirurgia de Pequenos Animais. 4.ed. Rio de Janeiro: Elsevier, pp.1295-1335.

10 Raul A., Rosa N., Yvonne E. \& Elisabet D. 2018. Assessment of the prevalence of gastric "gravel sign" in dogs with acute gastric dilatation-volvulus. Acta Veterinaria. 68(2): 161-167. DOI: 10.2478/acve-2018-0012

11 Sharp C.R., Rozanski E.A., Finn E. \& Borrego E.J. 2020. The pattern of mortality in dogs with gastric dilatation and volvulus. Journal of Veterinary Emergency and Critical Care. 30(2): 232-238. IDOI: 10.1111/vec.12932

12 Silva E.M.B., Albano M.B., Alberti H.A.A., Pereira Filho F.A., Namba M.M., Silva J.L.V. \& Cunha L.A.M. 2013. Lesões ligamentares do joelho: estudo biomecânico comparativo de duas técnicas de sutura em tendões: análise in vitro em tendões de bovinos. Revista Brasileira de Ortopedia. 48(1): 80-86. DOI: 10.1016/j.rboe.2012.07.001

13 Song K.K., Goldsmid S.E., Lee J. \& Simpson D.J. 2020. Retrospective analysis of 736 cases of canine gastric dilatation volvulus. Australian Veterinary Journal. 98(6): 232-238. DOI: 10.1111/avj.12942

14 Takeo M., Lee W. \& Ito M. 2015. Wound healing and skin regeneration. Cold Spring Harbor Perspectives in Medicine. 5(1): a023267. DOI: 10.1101/cshperspect.a023267

15 Urbanová L., Crha M., Raušer P. \& Nečas A. 2011. Clinical results and complications of preventive laparoscopic assisted gastropexy in 17 dogs: preliminary study. Acta Veterinaria Brno. 80(1): 93-99. DOI: 10.2754/avb201180010093

16 Willard M.D. 2015. Doenças do estômago. In: Nelson R. \& Couto C.G. (Eds). Medicina Interna de Pequenos Animais. 5.ed. Rio de Janeiro: Elsevier, pp.426-437. 